\title{
LIVER FUNCTION DERANGEMENT AND BLEEDING MORBIDITY IN DENGUE FEVER AND DENGUE HAEMORRHAGIC FEVER IN A TERTIARY HOSPITAL IN BANGLADESH
}

\author{
MD ARIFUZZAMAN ${ }^{1}$, AMIRUZZAMAN ${ }^{2}$, MD SADDAM HOSSAIN ${ }^{3}$, NAYLLA ISLAM $^{4}$, ABDULLAH AL NOMAN $^{5}$,
} BHABANANDA BAROI $^{6}$, TM SHAHANAWAZISLAM ${ }^{7}$, GOUTAM CHANDRA BHOWMIK ${ }^{8}$, MASUD-UR-RAHMAN ${ }^{9}$

\begin{abstract}
:
Background: Dengue is a major international health concern that is prevalent in tropical and sub tropical countries. Study of dengue infection and its Liver complications are scarce from countries like India. This study was done to assess the frequency and spectrum of liver dysfunction and bleeding morbidity in Dengue infection patients. Methods: A Cross sectional prospective observational study was performed in the of Department of Medicine Sir Salimullah Medical College Mitford Hospital. All the inpatients who were diagnosed with dengue infection between July 2015 to July 2016 were included in this study. A total of 70 patients were included in the study. Results: Patients were classified as classical dengue fever (DF) 61.5.\% dengue haemorrhagic fever (DHF) 38.5\%. The mean age was $28.607 \pm 10.45$ years in DF group and 26.78 11.78 years in DHF group and male: female ratio was 3:1. Deranged serum glutamic-oxaloacetic transaminase (SGOT) and/or Serum glutamic pyruvic transaminase (SGPT) was present in most of the patients. Elevation of ALT level occured more in DHF group patient (81\%) than DF group (46\%). Out of 70 patient $28(40 \%)$ patient were within normal value. 42 (60\%) patient had elevated ALT level which is statistically significant ( $p$ value-<0.05)..The degree of rise of SGOT, SGPT, and Bilirubin was significantly more in DHF and DSS, as compared to DF. About bleeding morbidity, purpura was a mentionable finding 29(41\%) but gum bleeding 15(21\%), echymosis 14(20\%), are less in both DF and DHF group. Major bleeding like hematomesis 5 (7\%), melaena 4 (5\%) and haematuria 1 (1\%) also occured in both group of patients. Conclusion: Liver dysfunction in the form of raised SGPT was seen in almost all patients. Preferentially high SGOT may serve as an early indicator of dengue infection while high values of bilirubin, SGOT, SGPT, may be an indicator of severe disease and poor prognosis.
\end{abstract}

Keywords: dengue infection, liver, bilirubin, heart failure, acute viral hepatitis

Received: 02.09.2021

Accepted: 09.11.2021 DOI: https://doi.org/10.3329/bjm.v33i1.56789

Citation: Arifuzzaman A, et al. Liver function derangement and bleeding morbidity in dengue fever and dengue haemorrhagic fever in a tertiary hospital in Bangladesh. Bangladesh J Medicine 2022; 33: 44-51.

1. Junior Consultant, Department of Medicine, Sir Salimullah Medical College,Mitford Hospital, Dhaka

2. Associate Professor, Department of Medicine, Sir Salimullah Medical College,Mitford Hospital, Dhaka

3. Registrar,Department of Medicine, Sir Salimullah Medical College,Mitford Hospital, Dhaka

4. Indoor Medical officer, Department of Medicine, Sir Salimullah Medical College,Mitford Hospital, Dhaka

5. Indoor Medical officer,Department of Medicine, Sir Salimullah Medical College,Mitford Hospital, Dhaka

6. Indoor Medical officer, Department of Medicine, Sir Salimullah Medical College, Mitford Hospital, Dhaka

7. Registrar,Department of Haematology, Sir Salimullah Medical College,Mitford Hospital, Dhaka

8. Assistant Registrar, National Institute of Cardiovascular Diseases Dhaka,, Bangladesh

9. Assistant Registrar, Department of Medicine, Sir Salimullah Medical College,Mitford Hospital, Dhaka

Address of Correspondence: Dr.Md Arifuzzaman, Junior Consultant, Department of Medicine, Sir Salimullah Medical College,Mitford Hospital, Dhaka,Mobile-01717555206 email -nomanssmc@gmail.com

Copyright: @2021 Associations of Physicians of Bangladesh 


\section{Introduction:}

Dengue is the most widely distributed mosquito-borne viral infection of humans, affecting up to 100 million persons each year across the tropical world.1,2 Dengue prevalence in Bangladesh was 2.7 per 1000 in 2019, which is gradually increasing. Infection with any of the four dengue viral serotypes may result in asymptomatic infection or may cause a range of disease manifestations from non-specific fever to a syndrome characterized by increased vascular permeability, thrombocytopenia, and deranged haemostasis. In severe cases, the increased vascular permeability results in circulatory compromise and the patient may develop potentially life-threatening dengue shock syndrome (DSS). ${ }^{2-4}$ No specific antiviral therapy is available but the physiologic derangements are transient, and most patients recover fully if supported with parenteral fluid therapy during the period of maximal vascular leakage. Current mortality rates for DSS are less than $1 \%$ in experienced hands. ${ }^{5-7}$

Dengue shock syndrome is an important cause of hospitalization among children living in dengueendemic areas. However, in general, severe bleeding is not a major problem in this group, despite often profound thrombocytopenia and clear evidence of a coagulopathy. ${ }^{8-10}$ In recent years, there has been a notable increase in the number of adults with dengue requiring hospitalization in Asia and South America. 6,11,12 Dengue shock syndrome appears to be less frequent in adults than children, possibly reflecting age-dependent differences in intrinsic vascular permeability, but there is anecdotal evidence to suggest that bleeding manifestations and hepatic dysfunction are both more common in older age groups. ${ }^{6,11,13}$ There have been few prospective studies focused on disease manifestations in adults, and there is little systematic data describing the clinical profile of disease in older patients or those with co-morbidities, or detailing the evolution of clinical and laboratory parameters through the various stages of the infection.

Hepatic dysfunction is a well recognized feature of dengue infections, often demonstrated by hepatomegaly and mild-to-moderate increases in transaminase levels although jaundice and acute liver failure are generally uncommon. ${ }^{14-17}$ Biopsy specimens obtained from a small number of patients with DSS who died have shown a variety of patterns including microvesicularsteatosis, hepatocellular necrosis with associated councilman bodies, Kupffer cell destruction, and inflammatory infiltrates at the hepatic portal tracts. ${ }^{18,19}$ Dengue antigens and viral RNA have been demonstrated in some of these fatal cases, and dengue viruses have been isolated occasionally from hepatic tissue. ${ }^{19-22}$ However, biopsy specimens are rarely obtained from less severe cases and the relevance of these findings to the broad spectrum of dengue infections remains uncertain. Debate continues as to whether dengue associated hepatic dysfunction indicates a direct viral effect, arises secondary to an aggressive host immune response to the virus, or reflects a complex interaction of these two mechanisms.

One factor that may influence the pattern of disease seen in adults is the greater likelihood of underlying chronic diseases, potentially compounding the effects of the acute infection. Chronic viral hepatitis is common among adults in many tropical and subtropical countries where dengue is endemic, and it has been postulated that dengue infection occurring on a background of chronic infection with hepatitis $B$ virus (HBV) or hepatitis $\mathrm{C}$ virus $(\mathrm{HCV})$ may result in more severe liver dysfunction and/or haemorrhage than is usual in non-infected persons. However, the evidence to date is conflicting; two small studies indicated no effect, ${ }^{14,15}$ and one study suggested that concomitant $\mathrm{HBV}$ infection may result in greater hepatic dysfunction.

\section{Methods:}

A hospital based cross sectional prospective observational study was performed in the of Department of Medicine Sir Salimullah Medical College Mitford Hospital. All the in patients (>13 years) who were diagnosed with dengue infection between July 2015 to July 2016 were included in this study. History, clinical features, Investigation and treatment given was collected from the records. Patients with pre existing or concurrent liver disease due to any other etiology were excluded from the study (e.g. diagnosed Chronic Liver Disease co- existing or recent history of infectious disease like acute viral hepatitis, malaria, typhoid, leptospirosis, history of intake of any hepatotoxic drugs, history of alcoholic liver disease, history of Non-alcoholic Fatty Liver Disease (NAFLD) Wilson's disease, autoimmune hepatitis and heart failure etc.). A total of 70 patients were included in the study. Patients were categorized in to classical dengue fever (DF), Dengue hemorrhagic fever, Dengue shock syndrome as per WHO criteria.16 Dengue infection was detected using Rapid test (Immunochromatography) for Dengue NS1 Antigen/IgM Dengue. Few were confirmed using ELISA for IgM Dengue.

\section{Statistical analysis}

Results for continuous variables were expressed as means and standard deviation. Categorical variables were expressed as percentages. Student's t-test for 
continuous variables and Chi square test for discrete variables were used to test significance. The $p$ value of less than 0.05 was considered statistically significant. The SPSS 22 software was used for statistical analysis.

\section{Results:}

A total number of 70 serologically confirmed patients were selected for this study. The cases of dengue patients mentioned throughout the study were divided into Dengue Fever (DF) and Dengue Hemorrhagic Fever (DHF). Dengue shock Syndrome cases were also identified but did not mention separately here.

While interpreting the results from the study, the demographic factors and general characteristics of the patients were analyzed. Bleeding manifestations of the DF and DHF were analyzed as well. Serum bilirubin level between respondents was identified. The analysis also comprises aminotransferase (ALT and AST) levels of patient's groups. The correlation and comparisons were done between different variables. All the results were presented in both tabular and diagram form.

Before the result analysis, the baseline information was analyzed and general characteristics were compiled.

The mean age of the respondents was $28.607 \pm 10.45$ years in DF group and $26.78 \pm 11.78$ years in DHF group. However, out of 70 patients, 43 patients were from the DF group and rest of the 27 patients was from DHF group. Most of the patients (34 patients) were from the age group of 21-30 years. The age group of 1320 years, 9 patients suffered from DF and 5 patients suffered from DHF. Only 1 patient was found from DF group, whose age was in between 51-60 years. In DF group, 34(49\%) patients were male and 9(12\%) were female. In DHF group, 6 patients were female and 21 patients were male. In total, 55(78\%) patients were male and $15(21 \%)$ patients were female. In both DF and DHF group male were more in number than female

In this study, occupational status of the respondents represents that, most of the patients with DF were engaged in service (14) and business (10). In DHF group, it was found that 6 patients were businessman, 7 were service holders and 2 were housewives. In total, it was found that most of the patients were service holders (21).

Pattern of fever among patients are shown in figure 1

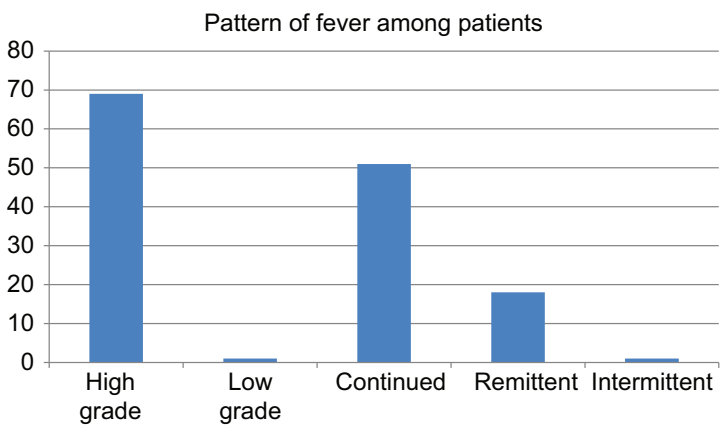

Fig.-1: Pattern offever among patients

Table-I

Bleeding profile of the patient

\begin{tabular}{|c|c|c|c|c|c|}
\hline & Type of patient & Total & $\mathrm{DF}$ & DHF & \\
\hline \multirow[t]{2}{*}{ Purpura } & Yes & 0 & 19 & 29 & \\
\hline & No & 33 & 8 & 41 & $<0.05$ \\
\hline Total & & 43 & 27 & 70 & \\
\hline \multirow[t]{2}{*}{ Echymosis } & Yes & 4 & 10 & 14 & \\
\hline & No & 39 & 17 & 56 & $<0.01$ \\
\hline Total & & 43 & 27 & 70 & \\
\hline \multirow[t]{2}{*}{ Gum bleeding } & Yes & 3 & 12 & 15 & \\
\hline & No & 40 & 15 & 55 & $<0.01$ \\
\hline Total & & 43 & 27 & 70 & \\
\hline \multirow[t]{2}{*}{ Nasal bleeding } & Yes & 0 & 6 & 6 & \\
\hline & No & 43 & 21 & 64 & $<0.01$ \\
\hline Total & & 43 & 27 & 70 & \\
\hline \multirow[t]{3}{*}{ Blood vomiting } & Yes & 0 & 5 & 5 & \\
\hline & No & 43 & 22 & 65 & $<0.01$ \\
\hline & Total & 43 & 27 & 70 & \\
\hline
\end{tabular}

${ }^{*} \mathrm{p}$ value calculated on basis of $z$-Test

In this table, purpura was present among 19 DHF patients and 10(23\%) DF patients. Ten patients had echymosis from DHF group and 4 patients from DF group. Nasal bleeding were found only 6 patients among DHF group. Gum bleeding had 12 patient from DHF and 3 from DF group. Besides, blood vomiting was found only 5 from DHF. 
Table-II

Other bleeding profile of the patient

\begin{tabular}{lccccc}
\hline & & \multicolumn{2}{c}{ Type of patient } & Total & \\
& & DF & DHF & & \\
\hline Haematuria & Yes & 0 & 1 & 1 & $<0.01$ \\
& No & 43 & 26 & 69 & \\
Total & & 43 & 27 & 70 & \\
Black tarry stool & Yes & 0 & 4 & 4 & \\
& No & 43 & 23 & 66 & $<0.01$ \\
Total & & 43 & 27 & 70 & \\
Blood mixed sputum & Yes & 0 & 1 & 1 & \\
& No & 43 & 26 & 69 & $<0.01$ \\
\hline Total & & 43 & 27 & 70 & \\
\hline
\end{tabular}

- P value calculated on basis of $z$-Test

This table showshaematuria was only 1 patient from DHF group. Black tarry stool was found among 4 patients from group DHF and not in DF. Blood mixed sputum was found only 1 patient in DHF but not in DF.

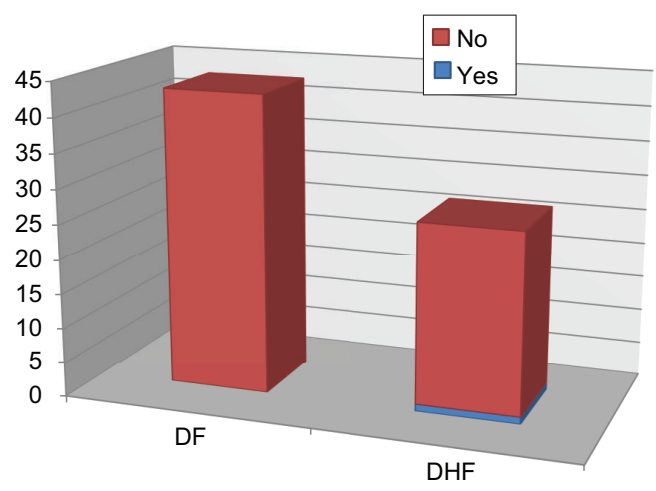

Fig.-2: Past history of Dengue among the patient

In this figure out of 43 patients of DF none had past history of dengue. In DHF group, out of 27 patients only one had past history of dengue.

Table-III

Value of Aminotransferase (AST) in study population $n=70$

\begin{tabular}{lccc}
\hline & \multicolumn{2}{c}{ Frequency } & P* \\
AST(SGOT) & DF & DHF & value \\
\hline Group $1(\leq 46 \mathrm{u} / \mathrm{L})$ & 24 & 2 & $<0.05$ \\
Group $2(47-120 \mathrm{u} / \mathrm{L})$ & 18 & 17 & $>0.05$ \\
Group $3(121-400 \mathrm{u} / \mathrm{L})$ & 1 & 7 & $<0.05$ \\
Group $4(\geq 400 \mathrm{u} / \mathrm{L})$ & 0 & 1 & $>0.05$ \\
\hline Total & 43 & 27 & \\
\hline
\end{tabular}

* P value calculated on basis of $z$-Test
In table-V, the value of AST is presented in 4(four) groups. Maximum patient's AST values was in group$2,35(50 \%)$ and in group-1, 26(37\%). In group-3, 8(11\%) patients had AST level was more than 3 to 8 times the upper normal limit. Only 1 patient was in group4. here only the value shows significant between DF and DHF in group-3.

Table-IV

Value of Aminotransferase (ALT) in study population $n=70$

\begin{tabular}{lccc}
\hline & \multicolumn{2}{c}{ Frequency } & $\mathrm{P}^{*}$ \\
AST(SGOT) & DF & DHF & value \\
\hline Group $1(\leq 50 \mathrm{u} / \mathrm{L})$ & 23 & 5 & $<0.05$ \\
Group $2(51-120 \mathrm{u} / \mathrm{L})$ & 18 & 8 & $>0.05$ \\
Group $3(121-400 \mathrm{u} / \mathrm{L})$ & 2 & 10 & $<0.05$ \\
Group $4(\geq 400 \mathrm{~L} / \mathrm{L})$ & 0 & 4 & $>0.05$ \\
\hline Total & 43 & 27 & \\
\hline
\end{tabular}

* P value calculated on basis of $z$-Test

In this table, the measured ALT level is divided into 4 group. Most of the patient was in Group- 1 and the number of patients was $28(40 \%)$. In group-2, total number of patients was $26(37 \%)$. Group-4 shows 4 patients had altered ALT, about 8 times more the above normal limit, in DHF group. In this table serum aminotransferase changes is statistically significant between DF and DHF group. 
Table V

Anti Dengue antibody (IgG) profile in study population $n=70$

\begin{tabular}{llcccc}
\hline & & \multicolumn{2}{c}{ Type of patient } & Total & P*value \\
& DF & DHF & & \\
\hline IgG & Positive & 25 & 19 & $44(62.8 \%)$ & $<0.05$ \\
& Negative & 18 & 8 & $26(37 \%)$ & \\
\hline & Total & 43 & 27 & 70 & \\
\hline
\end{tabular}

* P value calculated on basis of $z$-Test

In this table it is shown that out of total 70 patients, 44 (62.8\%) patients were IgG positive and 26 (37\%) patients were IgG negative. The difference in IgG positivity and negativity in DF and DHF patients were significant $(\mathrm{P}<0.05)$.

Table-VI

ANOVA test

Relationship between past history of dengue in DF or DHF

\begin{tabular}{lcccc}
\hline & Sum of Squares & df & $\begin{array}{c}\text { Mean square } \\
\text { Sum of Squares df }\end{array}$ & F \\
\hline Between & .649 & 1 & .649 & 4.185 \\
Groups & 10.551 & 68 & .155 \\
Within groups & 11.200 & 69 & \\
Total & & & \\
\hline
\end{tabular}

a. Predictors: (Constant), past history of dengue

b. dependent Variable: Type of patient

In this study the association between different variables across the study, patient's past history of dengue and its association with Dengue morbidity was also tested with a one way ANOVA test (Analysis of Variance). Hereby, experimental factor of past history of Dengue was to be distinguished by experimental groups of DF and DHF. And we may take a null $\left(\mathrm{H}_{0}\right)$ hypothesis that, past history of Dengue has no significance with DF and DHF. In this test, the using the regression model, the sum of square value between the groups was.649 at 1 degree of freedom. Besides, sum of squares value within groups was counted at 155 . However, the $F$ value was counted as $\mathrm{F}=.649 / .155=4.185 \mathrm{~F}$ value at $\mathrm{df} 1$ and 68 at $5 \%$ level of significance $=4.035$ (From the F-distribution table) which is lower than the calculated value of $F$ and thus the value of $\mathrm{p}<0.05$. Thus, null (HO) hypothesis may be counted as rejected and it has been found that past history is significant in DF and DHF.

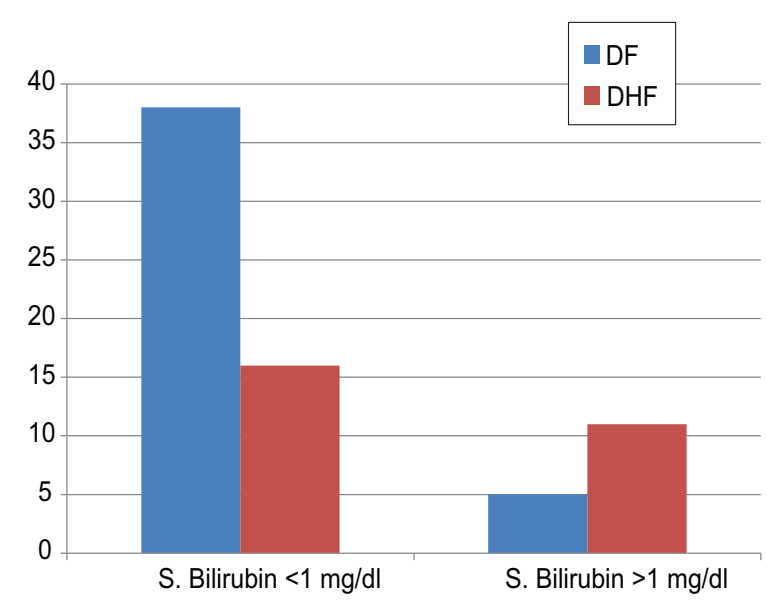

Fig.-3: Comparison of serum bilirubin between DF and DHF patients.

Above figure showed the comparison between $\mathrm{S}$. bilirubin among DF and DHF patients and found that the variance were relatively higher. 
Table-VII

AST and bleeding morbidity $n=70$

\begin{tabular}{lccc}
\hline & \multicolumn{2}{c}{ Bleeding morbidity } & P-value \\
AST & Yes & NO & \\
\hline AST normal & 16 & 10 & $<0.05$ \\
AST raised & 37 & 07 & \\
\hline Total & 53 & 17 & \\
$*$ P value calculated on the basis of $\mathrm{X}^{2}$ - test
\end{tabular}

In this table, the total number of patients of bleeding manifestations were 53in both DF and DHF. In raised AST level, the number of patients was 37. The ("p") value was $<0.05$. So there is significant relationship between raised AST and bleeding morbidity.

Table-VIII

ALT and bleeding morbidity $n=70$

\begin{tabular}{lccc}
\hline & \multicolumn{2}{c}{ Bleeding morbidity } & P-value \\
AST & Yes & NO & \\
\hline AST normal & 16 & 12 & $<0.05$ \\
AST raised & 37 & 05 & \\
\hline Total & 53 & 17 & \\
\hline
\end{tabular}

${ }^{*} \mathrm{P}$ value calculated on the basis of $\mathrm{X}^{2}$ - test

In this table there is also significant between raised serum ALT level and bleeding morbidity in DF and DHF.

\section{Discussion:}

In Bangladesh, the magnitude of Dengue fever was largely unknown until an epidemic of DF and DHF broke out in June, 2000. Since then, it has become endemic here.Dengue prevalence in Bangladesh was 2.7 per 1000 in 2019, which is gradually increasing

A total number of 70 serologically confirmed (IgM +ve) Patients were selected for the study. The cases of dengue patients in this study were divided into Dengue Fever (DF) and Dengue Hemorrhagic fever (DHF).

Out of total 70 patient maximum patients were from the age group of 21 to 30 years and is $34(49 \%)$. The mean age of DF patient was 28.6 $110.45 y$ years and DHF patient was $26.78 \pm 11.78$ years. In the study of Farizshafhan et al, (2008) the mean age was $31 \pm 12$ years and Luiz Jose de Souza et al, (2004) the mean age was $35.5 \pm 16.3$ years that are nearer to this study.

In this study, 21\% (15) patient was female, 78\% (55) patient was male (figure-7). Male patients were almost
3 times than female in both DF and DHF group. In SrivenuItha et al, (2005) study out of 55 patient 29 were male and 16 were female where male is about 2 times more than female. In our society male are empowered and they are the main earning source. So they are privileged for medical treatment.

In occupation, out of 70 patient, maximum (21) were service holder followed by 16 were business man. This is due to the fact that most of the patient came from urban and peri-urban area. In Buke $T$ (1968) and Wichmann O (2007) study maximum patients were service holder and businessman.

According to patient statement, no past history of Dengue was found in 56 patients from DF group, bit only 1 patient from DHF group who had a past history of Dengue. But in table 7, out of 70 patient $44(63 \%)$ had IgG +ve. This indicates that in majority cases past history of dengue remains unidentified.

Most of the patients serum bilirubin level was below the normal range in both DF and DHF group. only 16 $(22 \%)$ had above $1 \mathrm{mg} / \mathrm{dl}$. Statistically it is significant in DF and DHF group (pvalue<0.01).

About bleeding morbidity, purpura was a mentionable finding 29(41\%) but gum bleeding 15(21\%), echymosis $14(20 \%)$, are less in both DF and DHF group. Major bleeding like hematomesis 5 (7\%), melaena 4 (5\%) and haematuria 1 (1\%) also occured in both group. As a whole the bleeding profile of dengue patient in both group is statistically significant. In study of FarizSafhan et al, shows major bleeding $-14.6 \%$, minor bleeding $36.8 \%$. So this study showed significant association existed between bleeding outcome and dengue patient. In majority, bleeding is not severe and improve spontaneously. However, we should be cautious about bleeding and not to use aspirin or antiplatelet drug in dengue.

\section{Conclusion:}

Liver damage is a common complication of dengue infection and aminotransferase levels are a valuable marker for monitoring these cases. These changes are not life threatening and the level of serum aminotransferase will become normal spontaneously.

\section{Limitation of the Study:}

The study was a hospital based and only a small number of respondents were taken. Patients from all socioeconomic status and all parts of the country did not come to seek medical attention in the study place.. Due to financial constrain much of the tests was not possible to cross check the results of serological findings for acute precision and accuracy. It will be more authentic if this study can be done on 
a large population group in more institutions with longer duration of study.

\section{Acknowledgement:}

Thankful to all doctors, nurses and medical stuff of Department of Medicine, Sir Salimullah Medical College Mitford Hospital; Dhaka, Bangladesh for their best and kind support for collection of data for this study.

\section{Declaration of interest:}

The authors report no conflict of interest.

\section{Funding:}

The author(s) received no financial support for the research, authorship, and/or publication of this article.

\section{Ethical consideration:}

The study was conducted after approval from the ethical review committee. The confidentiality and anonymity of the study participants were maintained.

\section{References:}

1. Mackenzie JS, Gubler DJ, Petersen LR. Emerging flaviviruses: the spread and resurgence of Japanese encephalitis, West Nile and dengue viruses. Nat Med. 2004;10:S98-S109. https://doi.org/10.1038/ nm1144. PMid: 15577938

2. Halstead SB. Dengue. Lancet.2007;370:1644-1652. https:/ / doi.org/10.1016/S0140-6736(07)61687-0

3. AlvarezM.E,Ramirez-Ronda C.H.Dengue and hepatic failure.Am J Med 1985;79(5):670-4. https://doi.org/ 10.1016/0002-9343(85)90070-1

4. World Health Organization.Dengue: Guideline for Diagnosis, Treatment, Prevention and Control. Geneva: World Health Organization; 2009.

5. Harris E, Videa E, Perez L,et al. Clinical, epidemiologic, and virologic features of dengue in the 1998 epidemic in Nicaragua. Am J Trop Med Hyg.2000;63:5-11. https://doi.org/10.4269/ ajtmh.2000.63.5. PMid:11357995

6. Wichmann O, Hongsiriwon S, Bowonwatanuwong $\mathrm{C}$,et al. Risk factors and clinical features associated with severe dengue infection in adults and children during the 2001 epidemic in Chonburi, Thailand. Trop Med Int Health.2004;9:1022-1029. https:// doi.org/10.1111/j.1365-3156.2004.01295.x PMid:15361117

7. Wills BA, Nguyen MD, Ha TL,et al. Comparison of three fluid solutions for resuscitation in dengue shock syndrome.N Engl J Med. 2005;353:877-889. https: / / doi.org/ 10.1056 / NEJMoa044057. PMid:16135832

8. Wills BA, Oragui EE, Stephens AC,et al. Coagulation abnormalities in dengue hemorrhagic fever: serial investigations in 167 Vietnamese children with dengue shock syndrome. Clin Infect Dis. 2002;35:277-285. https://doi.org/10.1086/341410 PMid: 12115093

9. Carlos CC, Oishi K, Cinco MT,et al. Comparison of clinical features and hematologic abnormalities between dengue fever and dengue hemorrhagic fever among children in the Philippines. Am J Trop Med Hyg. 2005;73:435-440. https://doi.org/10.4269/ ajtmh.2005.73.435. PMid:16103617

10. Wills B, Tran VN, Nguyen TH,et al. Hemostatic changes in Vietnamese children with mild dengue correlate with the severity of vascular leakage rather than bleeding. Am J Trop Med Hyg.2009;81:638644. https://doi.org/10.4269/ajtmh.2009.08-0008. PMid: 19815879

11. Kittigul L, Pitakarnjanakul P, Sujirarat D, Siripanichgon K. The differences of clinical manifestations and laboratory findings in children and adults with dengue virus infection.J ClinVirol.2007;39:76-81. https://doi.org/10.1016/ j.jcv.2007.04.006. PMid:17507286

12. Ong A, Sandar M, Chen MI, Sin LY. Fatal dengue hemorrhagic fever in adults during a dengue epidemic in Singapore.Int J Infect Dis. 2007;11:263267. https://doi.org/10.1016/j.ijid.2006.02.012. PMid:16899384

13. Wang CC, Lee IK, Su MC, Lin HI, Huang YC, Liu $\mathrm{SF}, \mathrm{Wu} \mathrm{CC}$, Lin MC. Differences in clinical and laboratory characteristics and disease severity between children and adults with dengue virus infection in Taiwan, 2002. Trans $\mathrm{R}$ Soc Trop Med Hyg.2009;103:871-877. https://doi.org/10.1016/ j.trstmh.2009.04.024. PMid:19500813

14. Kuo CH, Tai DI, Chang-Chien CS, Lan CK, Chiou SS, Liaw YF. Liver biochemical tests and dengue fever. Am J Trop Med Hyg.1992;47:265-270. https:/ / doi.org/10.4269/ajtmh.1992.47.265. PMid: 1355950

15. Nguyen TL, Nguyen TH, Tieu NT. The impact of dengue haemorrhagic fever on liver function.Res Virol.1997;148:273-277. https://doi.org/10.1016/ S0923-2516(97)88364-1

16. Souza LJ, Alves JG, Nogueira RM, GicovateNeto C, Bastos DA, Siqueira EW, SoutoFilho JT, CezarioTde A, Soares CE, CarneiroRda C. Aminotransferase changes and acute hepatitis in patients with dengue fever: analysis of 1,585 cases. Braz J Infect Dis. 2004;8:156-163. https://doi.org/10.1590/S141386702004000200006. PMid:15361994

17. Mohan B, Patwari AK, Anand VK. Hepatic dysfunction in childhood dengue infection.J Trop Pediatr.2000;46:40-43. https://doi.org/10.1093/ tropej/46.1.40. PMid:10730040 
18. Bhamarapravati N. Hemostatic defects in dengue hemorrhagic fever. Rev Infect Dis. 1989;11((Supp1 4)):S826-S829. https://doi.org/10.1093/clinids / 11.Supplement_4.S826. PMid:2665014

19. Huerre MR, Lan NT, Marianneau P, Hue NB, Khun H, Hung NT, Khen NT, Drouet MT, Huong VT, Ha DQ, Buisson Y, Deubel V. Liver histopathology and biological correlates in five cases of fatal dengue fever in Vietnamese children. Virchows Arch. 2001;438:107-115.

20. Rosen L, Khin MM., U T Recovery of virus from the liver of children with fatal dengue: reflections on the pathogenesis of the disease and its possible analogy with that of yellow fever. Res
Virol.1989;140:351-360. https://doi.org/10.1016/ S0923-2516(89)80115-3

21. Rosen L, Drouet MT, Deubel V. Detection of dengue virus RNA by reverse transcription-polymerase chain reaction in the liver and lymphoid organs but not in the brain in fatal human infection. Am J Trop Med Hyg.1999;61:720-724. https://doi.org/ 10.4269/ajtmh.1999.61.720. PMid:10586901

22. Jessie K, Fong MY, Devi S, Lam SK, Wong KT. Localization of dengue virus in naturally infected human tissues, by immunohistochemistry and in situ hybridization. J Infect Dis. 2004;189:14111418. https://doi.org/10.1086/383043. PMid: 15073678 . 